\title{
Rupture process of the largest aftershock of the $M 9$ Tohoku-oki earthquake obtained from a back-projection approach using the MeSO-net data
}

\author{
Ryou Honda $^{1}$, Yohei Yukutake ${ }^{1}$, Hiroshi Ito ${ }^{1}$, Masatake Harada ${ }^{1}$, Tamotsu Aketagawa ${ }^{1}$, Akio Yoshida $^{1}$, Shin ichi Sakai $^{2}$, \\ Shigeki Nakagawa ${ }^{2}$, Naoshi Hirata ${ }^{2}$, Kazushige Obara ${ }^{2}$, Makoto Matsubara $^{3}$, and Hisanori Kimura ${ }^{3}$ \\ ${ }^{1}$ Hot Springs Research Institute of Kanagawa Prefecture, 586 Iriuda, Odawara, Kanagawa 250-0031, Japan \\ ${ }^{2}$ Earthquake Research Institute, University of Tokyo, 1-1-1 Yayoi, Bunkyo-ku, Tokyo 113-0032, Japan \\ ${ }^{3}$ National Research Institute for Earth Science and Disaster Prevention, 3-1 Tennodai, Tsukuba, Ibaraki 305-006, Japan \\ (Received August 15, 2012; Revised January 7, 2013; Accepted January 14, 2013; Online published September 17, 2013)
}

\begin{abstract}
The largest aftershock $\left(M_{\mathrm{w}} 7.8\right)$ of the giant $M 9.0$ Tohoku-oki earthquake occurred near the coast of Ibaraki Prefecture about thirty minutes after the main shock. We have imaged the rupture process of the $M_{\mathrm{w}} 7.8$ earthquake by back-projection of waveform data from the Metropolitan Seismic Observation network (MeSOnet). Original acceleration seismograms were integrated. They were then band-pass filtered in the frequency range of $0.1-1.0 \mathrm{~Hz}$. We assumed a fault plane on the plate boundary with a dimension of $115 \mathrm{~km} \times 175 \mathrm{~km}$, and this was divided into 112 subfaults. Travel times from each of the subfaults to observation sites were calculated by using a 3-D velocity structure model. Applying the restrictions that the rupture velocity is smaller than 4 $\mathrm{km} / \mathrm{s}$ and the rupture duration on each subfault is less than $25 \mathrm{~s}$, we obtained a rupture propagation image by projecting the power of the stacked waveforms. Propagation of the rupture toward north and east was suppressed by the existence of those areas that had radiated a large seismic energy at the main shock occurrence, or at the occurrence of the $M 7.0$ earthquake in 2008. The westward propagation of the rupture stopped at the area where the Philippine Sea plate lies over the Pacific plate.
\end{abstract}

Key words: Rupture process, back projection, 2011 Ibaraki-oki, MeSO-net.

\section{Introduction}

The largest aftershock of the 2011 off the Pacific coast of Tohoku Earthquake (the 2011 Tohoku-oki earthquake in the following) occurred near the coast of Ibaraki Prefecture at 15:15 on March 11, 2011, 30 minutes after the main shock (Fig. 1(a)). The moment magnitude of the earthquake was $M_{\mathrm{w}} 7.8$ (NIED, 2012). This is comparable to the $M_{\mathrm{w}} 7.9$ of the 1923 Kanto earthquake (Kanamori, 1977) that occurred at the Sagami Trough causing serious damage in the metropolitan area.

There is no historical record of a great ( $M 8$ class or larger) earthquake around the hypocenter of the largest aftershock (Utsu, 1999). The seismic catalogue of the Japan Meteorological Agency (JMA) shows that large earthquakes $(M>6)$ are relatively few in the vicinity of the largest aftershock after 1923, though $M$ 7-class earthquakes occurred recurrently to the east of the area (Fig. 1(b)).

The seismic gap of large earthquakes may reflect the mode of the plate coupling in the region. In the Kanto region, the Philippine Sea plate subducts northwestward from the Sagami Trough and the Pacific plate subducts westward beneath the Philippine Sea plate from the Japan Trench. Several studies have estimated the plate coupling rate around the source region of the largest aftershock (the

Copyright (C) The Society of Geomagnetism and Earth, Planetary and Space Sciences (SGEPSS); The Seismological Society of Japan; The Volcanological Society of Japan; The Geodetic Society of Japan; The Japanese Society for Planetary Sciences; TERRAPUB.

doi:10.5047/eps.2013.01.003
2011 Ibaraki-oki event in the following). In the region off Ibaraki Prefecture, to the south of the source area of the main shock (Honda et al., 2011), the plate contacting with the Pacific plate changes from the North American plate to the Philippine Sea plate. The hypocenter of the 2011 Ibaraki-oki event was on the plate boundary between the North American plate and the Pacific plate. From a study of repeating earthquakes on the plate boundaries, Uchida $e t$ al. (2009) considered that the coupling coefficient between the Pacific plate and the North American plate is relatively large compared with that between the Pacific plate and the Philippine Sea plate. However, the coupling strength in the focal region of the 2011 Ibaraki-oki event cannot be inferred from such an analysis, for there is no repeating earthquake there. Nishimura et al. (2007) estimated the plate coupling rate in and around the Kanto region using GPS data. According to their result, the 2011 Ibaraki-oki event is located at the border of the areas of low and high coupling rates.

In this study, we investigate the rupture process of the 2011 Ibaraki-oki event by using the back-projection approach, and we discuss tectonic situations that might have caused the rupture to stop.

\section{Data and Method}

In the analysis, we used data of strong ground motion obtained by the Metropolitan Seismic Observation network (MeSO-net) that has been developed under the "Special Project for Earthquake Disaster Mitigation in Tokyo Metropolitan Area" which started in 2007 (Fig. 2(a)). Data 

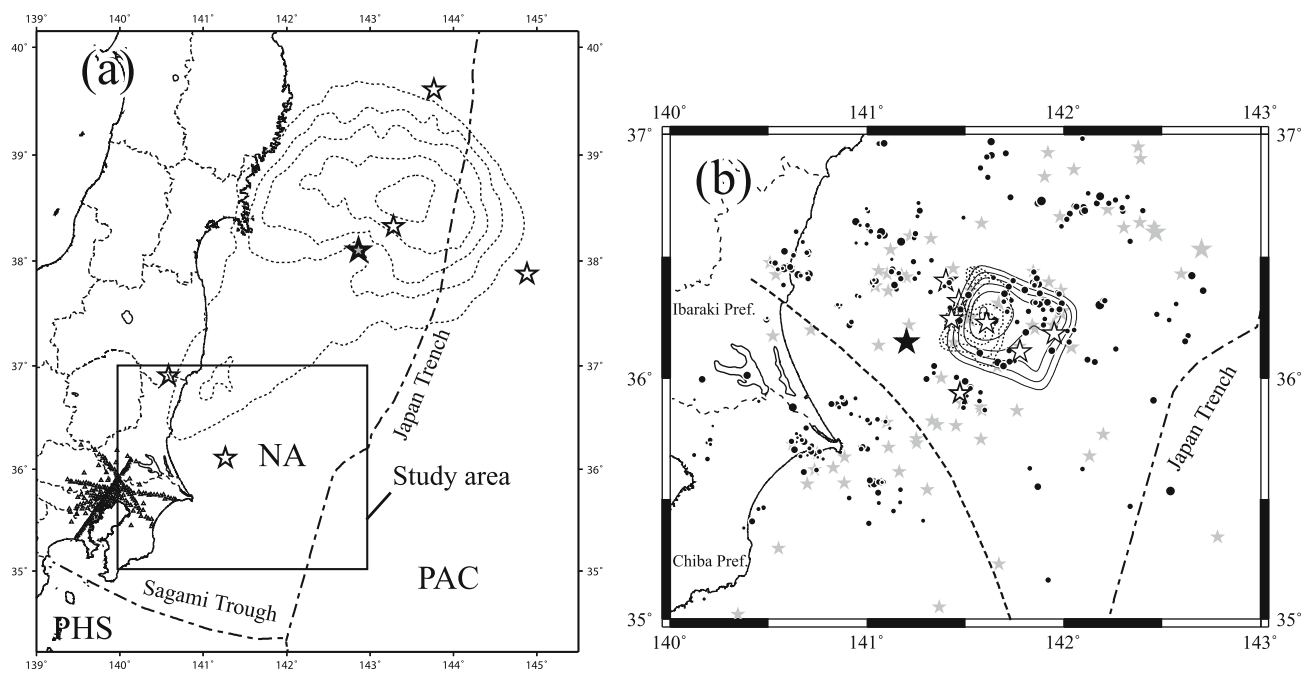

Fig. 1. (a) Geographic map showing epicenters of the main shock of the 2011 Tohoku-oki earthquake (gray star) and aftershocks with magnitudes larger than 7 (white stars). Dotted contour lines show the strength distribution of the radiation energy (greater than $50 \%$ of the maximum value) for the main shock occurrence which was obtained by Honda et al. (2011) using the back-projection approach. The Japan Trench and the Sagami Trough are shown by dot-dashed lines. Small triangles represent observation sites of the MeSO-net. NA, PHS and PAC indicate the North American plate, Philippine Sea plate and Pacific plate, respectively. (b) The black star is the epicenter of the 2011 Ibaraki-oki event. White stars are epicenters of $M 7$-class earthquakes which have been regarded as characteristic earthquakes and gray stars show epicenters of large earthquakes $(M>6)$. Black dots indicate repeating small earthquakes reported by Kimura et al. (2006). A thick dashed line shows the north-eastern end of the PHS that lies on the PAC. Contours by dotted lines and solid lines represent slip distributions of $M 7$ earthquakes that occurred in 1982 (Murotani et al., 2003 ) and 2008 (Nagoya Univ., 2008), respectively.
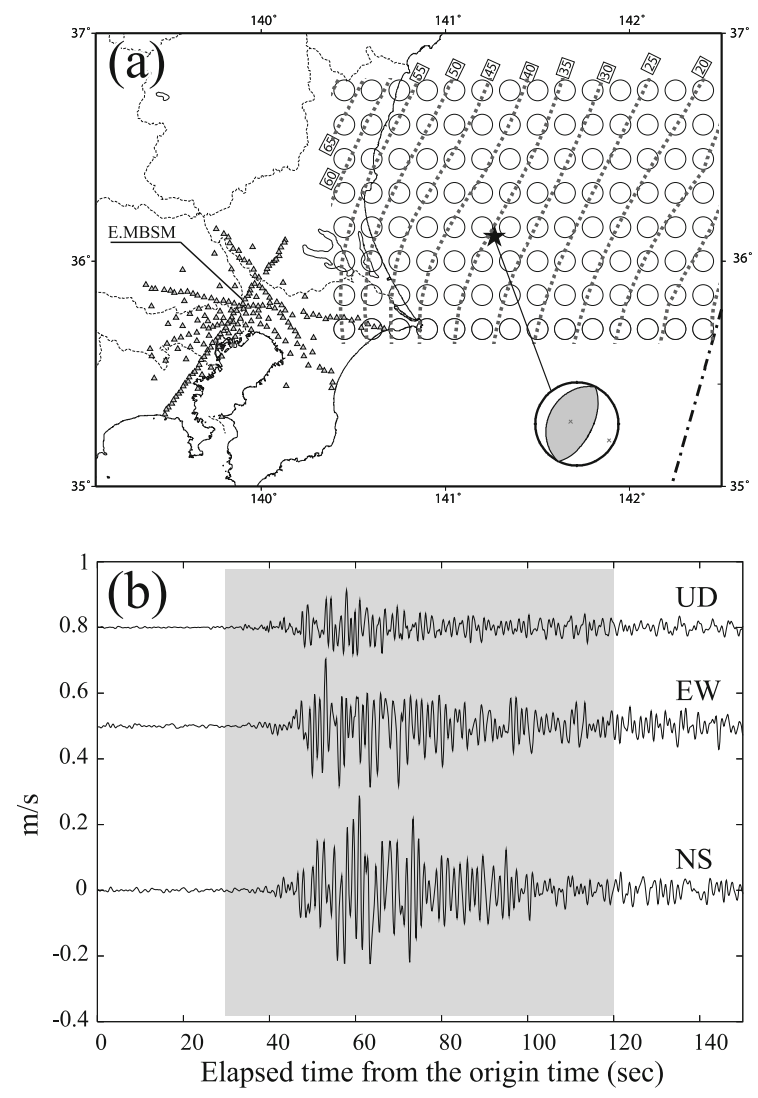

Fig. 2. (a) Distribution of observation sites (triangles) and subfaults (circles) used in this study. Contour lines overlapping the circles indicate the depth of the upper surface of the Pacific plate (Nakajima and Hasegawa, 2009). The epicenter of the largest aftershock is shown by a black star together with the F-net CMT solution. The dot-dashed line is the same as that in Fig. 1. (b) Velocity waveforms in a frequency range of $0.1-1.0 \mathrm{~Hz}$ observed at the reference site E.MBSM. Horizontal waveforms in the shaded time window are used in the analysis. of strong ground motions at 249 stations installed in and around the Tokyo Metropolitan Area are automatically transmitted to the operation center in the Earthquake Research Institute (ERI) in real time. The extent of the MeSOnet is over $100 \mathrm{~km}$ and station separations are mostly several kilometers only. We regarded the MeSO-net as a seismic array and investigated the rupture process of the 2011 Ibaraki-oki event by adopting the back-projection method.

Sources of seismic energy which arrived at the array from the assumed fault plane are estimated by making slant stacking of seismograms taking account of the travel time differences. To suppress high frequency components that cause noises in the projected image and to compare the result with those obtained by inversion methods that usually use velocity data, original acceleration seismograms are integrated into velocity. They were then band-pass filtered in a frequency range of $0.1-1.0 \mathrm{~Hz}$. We used two horizontal components of waveforms in a $90 \mathrm{~s}$ time window including $S$-wave at the reference site (Fig. 2(b)). Before carrying out the stacking operations, waveforms from each subfault are transformed to radial and transverse components (i.e., $S V$ - and $S H$-waves). The horizontal seismogram at the $i$ th station $x_{i}(\tau)$ is expressed by the following equation, after correcting the effects of geometrical spreading and the radiation pattern:

$$
x_{i}(\tau)=\left(R_{i j} / \psi_{i j}\right) f_{i}(\tau)
$$

where $f_{i}(\tau), R_{i j}$ and $\psi_{i j}$ are the radial or transverse component of the horizontal waveform, travel distance from the $j$ th subfault to the $i$ th site, and the radiation pattern of the $S V$ or $S H$ wave for the $j$ th subfault, respectively. In the correction of the radiation pattern, the same source mechanism was assumed for the entire fault plane. We set the strike, 
dip and rake angles at 209, 31, and 92 degrees, respectively, after the F-net CMT solution (NIED, 2012).

Results of the stacking are influenced by phases of seismic waves with very similar arrival times. To enhance the resolution, $N$ th root stacking (e.g., Rost and Thomas, 2002) was applied. A stacked waveform $u_{j}(t)$ for the $j$ th subfault is calculated by the following equations:

$$
\begin{aligned}
& t=\tau-t_{j}^{\mathrm{ref}} \\
& u_{j}(t)=\frac{1}{M} \sum_{i=1}^{M}\left|x_{i}\left(t-d t_{i j}\right)\right|^{1 / N} \frac{x_{i}\left(t-d t_{i j}\right)}{\left|x_{i}\left(t-d t_{i j}\right)\right|},
\end{aligned}
$$

where $t_{j}^{\text {ref }}$ is the $S$-wave travel time from the $j$ th subfault to the reference site. The travel times were calculated by using a 3-D velocity structure model (Matsubara and Obara, 2011). $d t_{i j}$ represents the $S$-wave travel time difference between the reference site and station $i$ when subfault $j$ is assumed as the source. $M$ is the total number of stations used in the stacking procedure. After that, a stacked waveform is taken to the $N$ th power.

$$
U_{j}(t)=\left|u_{j}(t)\right|^{N} \frac{u_{j}(t)}{\left|u_{j}(t)\right|} .
$$

The $N$ th root stacking corresponds to the normal slant stacking when $N=1$. Integration of $\left|U_{j}(t)\right|$ for a particular subfault is considered to be proportional to the total energy radiated at the subfault.

In addition to the $N$ th root stacking, we introduced a semblance value to enhance coherent waves (Matsumoto et al., 1999). The semblance value is defined by the following equation:

$$
S_{j}(t)=\frac{\sum_{k=1}^{K}\left(\sum_{i=1}^{M} x_{i}\left(t_{k}-d t_{i j}\right)\right)^{2}}{K \sum_{k=1}^{K}\left(\sum_{i=1}^{M} x_{i}^{2}\left(t_{k}-d t_{i j}\right)\right)},
$$

where $K$ is the number of data in a semblance time window that is centered at time $t$. In this paper, we selected $N=4$ and set the length of the semblance time window to be $4 \mathrm{~s}$.

The final stacked wave $F_{j}(t)$ is expressed as:

$$
F_{j}(t)=S_{j}(t) \cdot U_{j}(t) .
$$

Integration of $\left|F_{j}(t)\right|$ for a particular subfault can be regarded as the total energy radiated at the subfault. The radiated energy distribution is then obtained by projecting the integration of $\left|F_{j}(t)\right|$ on to the corresponding subfault. After individual operations for the radial and transverse waveforms, we obtain the final result by averaging the radiated energy obtained from the two components.

To suppress noises that cause the appearance of pseudo rupture images, we put restrictions on the rupture velocity to be smaller than $4 \mathrm{~km} / \mathrm{s}$ and on the rupture duration at each subfault to be less than $25 \mathrm{~s}$. Even if a longer duration time (e.g., $90 \mathrm{~s}$ at each subfault) is assumed, the result is not changed substantially.

In this study, the hypocenter given by the JMA $(141.265 \mathrm{E}, 36.108 \mathrm{~N}, 35 \mathrm{~km})$ was adopted for the 2011
Ibaraki-oki event. Around the hypocenter a fault plane with a length of $115 \mathrm{~km}$ and a width of $175 \mathrm{~km}$ was taken and this was divided into subfaults with a dimension of $0.15 \times 0.15$ degree. Each subfault was clipped at the depth of the upper boundary of the Pacific plate which was modeled by Nakajima and Hasegawa (2009). The total number of subfaults is 112. Figure 2(a) shows the configuration of the fault model.

\section{Results}

To confirm the validity of our approach, we conducted a test using an aftershock $\left(M_{\text {jma }} 6.8\right)$ which occurred at 17:19 (JST) on March 11, 2011. It was found that the back projection image for the aftershock is in good agreement with the location of the JMA hypocenter (Fig. 3(a)). Figure 3(b) shows the distribution of the normalized total energy release on the assumed fault plane for the 2011 Ibaraki-oki event. Strong seismic energy was radiated from the region adjoining the major slip area at the 2008 Ibaraki-oki event. The maps in Fig. 4 are snapshots showing the propagation of the rupture. The rupture propagated from the hypocenter to the west (downdip) in 9 21 s after its initiation, and stopped at the region where strong seismic energy had been radiated from the 2011 Tohoku-oki earthquake. It is also notable that the rupture did not propagate beyond the north-eastern end of the Philippine Sea plate (Ucnida et al., 2009). Figure 5 shows the time function of the radiated energy. In the first 6 seconds, the energy release rate rose slowly, and it increased rapidly during the next $6 \sim 15$ seconds. Very small energy was radiated past 35 seconds. The total duration time of the rupture is about $40 \mathrm{~s}$ and a large part of the energy was radiated during $15 \sim 25 \mathrm{~s}$ after the initiation of the rupture.
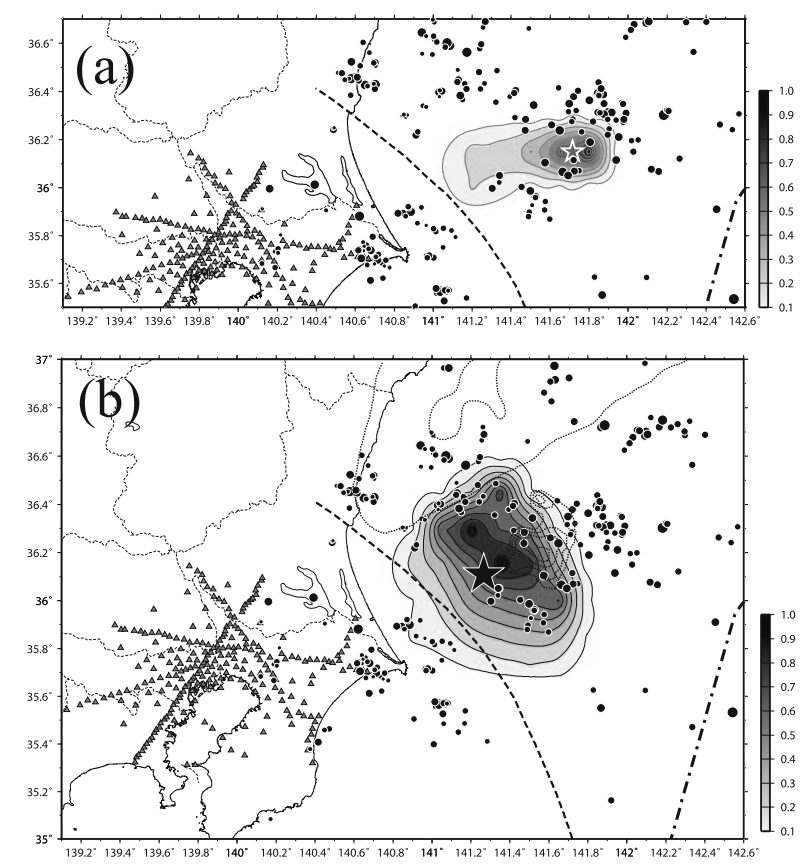

Fig. 3. (a) Normalized strength distribution of the radiated energy obtained by applying the back projection approach to an aftershock which occurred at 17:19 (JST) on March 11, 2011. The white star is the epicenter. A thick dashed line, a dot-dashed line, triangles and black dots are the same as those in Fig. 1(b). (b) Same as (a) except for the 2011 Ibaraki-oki event. Contours by dotted lines are the same as those in Fig. 1(b). The black star indicates the epicenter. 


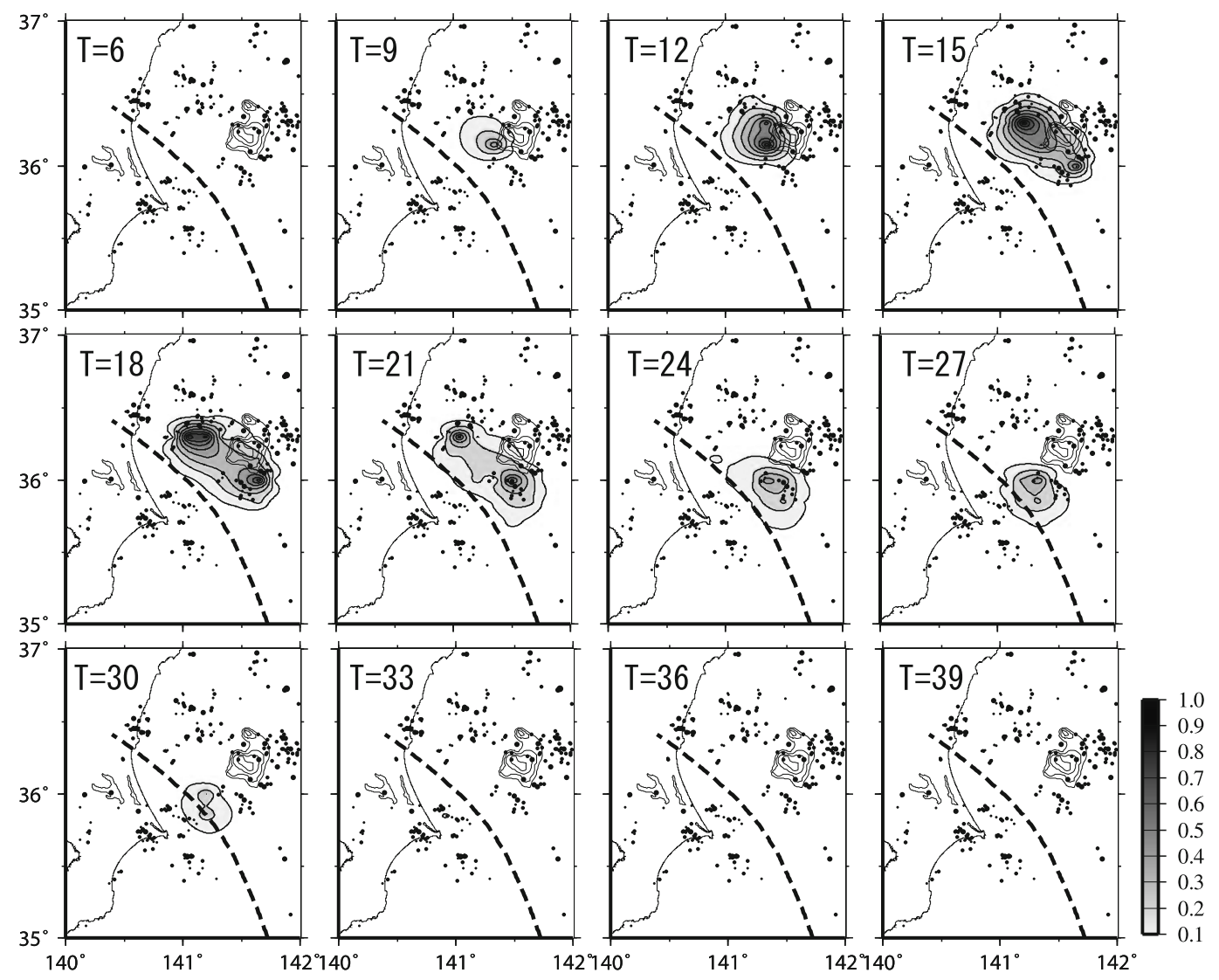

Fig. 4. Snap shots of the rupture propagation at intervals of 3 seconds. The rupture propagated westward generally. Its propagation to the south is seen to have stopped at the north-eastern end of the subducted Philippine Sea plate designated by a thick dashed line.

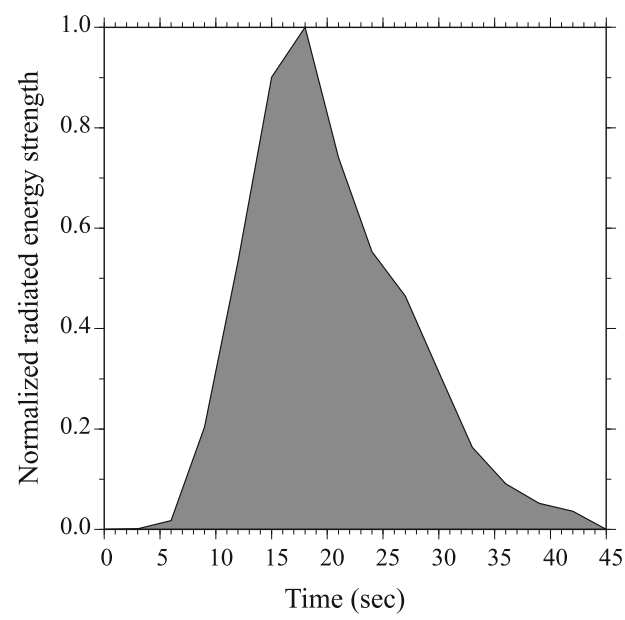

Fig. 5. The normalized time function of the radiated energy.

\section{Discussion and Conclusions}

From Fig. 3(b), it is seen that the area where greater than $10 \%$ or more, of the peak value was radiated extended over a region of about $100 \mathrm{~km} \times 100 \mathrm{~km}$ around the hypocenter (Fig. 3(b)). The distribution of the radiation strength during the 2011 Tohoku-oki earthquake obtained by the back projection approach, using MeSO-net, K-NET and KiKnet data from NIED (Honda et al., 2011), is also plotted in Fig. 3(b). Note that the north-western end of the rupture area of the 2011 Ibaraki-oki event is delineated by the area where substantial seismic energy, greater than $50 \%$ of the maximum value, was radiated at the main shock. On the other hand, the rupture area overlaps partly with the focal region of an $M 7$ earthquake that occurred on May 8, 2008. Around the source area of the 2008 Ibaraki-oki event, M 7class earthquakes are known to have occurred at an interval of about 20 years (Earthquake Research Committee, 2012). The estimated rupture areas of the past two events (1982 and 2008) are plotted in Fig. 1(b). Large parts of them overlap. (Murotani et al., 2003; Nagoya Univ., 2008). Although it is seen that a certain amount of energy was radiated from the rupture area of the 2008 Ibaraki-oki event, the radiation strength diminishes rapidly on the eastern side of the area. This suggests that the rupture that propagated eastward of the 2011 Ibaraki-oki event was suppressed when it entered into the recently ruptured area.

The strongly-radiated area corresponds to a gap of large earthquakes $(M>6)$ and repeating small earthquakes. From the occurrence rate of repeating small earthquakes, Uchida et al. (2009) estimated that the interplate coupling coefficient between the North American plate and the Pacific plate is $0.7 \sim 0.8$. Our results suggest that the rupture of the 2011 event which initiated at the strongly-coupled area extended to the region where interplate coupling had been partly released by stable slips. Another notable finding is that the rupture stopped at the northeastern end of the Philippine Sea plate (dashed line in Figs. 3 and 4). Based on the calculation of accumulated slips using repeating earthquakes, Uchida et al. (2009) estimated that the interplate 
coupling coefficient between the Philippine Sea plate and the Pacific plate is smaller than 0.5. This is smaller than that between the Pacific plate and the North American plate. It is very probable that the weakness of the interplate coupling suppressed the rupture from extending further beyond the border.

Our results indicate that the area around the hypocenter was a strong source of the radiated seismic energy ( $>0.8$ in Fig. 3). However, we cannot comment on the magnitude of the slip there. Performing a nonlinear inversion using GPS data, Nishimura et al. (2011) estimated $3.76 \pm 0.5 \mathrm{~m}$ as the average amount of the slip on a rectangular fault that almost overlaps with the rupture area. If the radiated energy distribution (Fig. 3(b)) is supposed to correspond to the slip distribution on the fault, the maximum slip could have reached $7 \sim 8 \mathrm{~m}$. This is a reasonable amount of slip for an $M 8$ class earthquake. However, the estimated slip is considerably smaller compared with the slip deficit predicted by the relative plate velocity of $8.3 \mathrm{~cm} / \mathrm{y}$ (DeMets et al., 1994), or $7.2 \mathrm{~cm} / \mathrm{y}$ (Sella et al., 2002), if we note that there has been no record of large earthquakes there during the past several hundred years (Utsu, 1999). This may imply that a substantial part of the accumulated strain might have been released in another way, for example, by aseismic slips (e.g., Seno, 2012). We think it may also be possible that the accumulated strain still remained in a large area, including the focal region of the 2011 Ibaraki-oki event. In that case, the southeastern part of the fault plane where seismic energy was not radiated much at the 2011 Ibaraki-oki event is a potential source region of a future large earthquake.

From seismic surveys, Mochizuki et al. (2008) deduced the existence of a seamount in the region near the Japan Trench. The seamount could be a barrier of the rupture during the 2011 Ibaraki-oki event. This idea agrees with strong plate coupling in that region estimated from GPS data (Nishimura et al., 2007). On the other hand, Mochizuki et al. (2008) maintains weak interplate coupling around the seamount from the results of seismic surveys and laboratory experiments. In any case, whether the coupling strength at the region near the Japan Trench is strong or weak, we think much attention should be paid to the seismic activity and/or afterslip there.

Acknowledgments. The present work was supported by JSPS KAKENHI Grant Number 24740314 and the Special Project for Earthquake Disaster Mitigation in Tokyo Metropolitan Area of the Japanese Ministry of Education, Culture, Sports, Science and Technology (MEXT). We used digital data of the upper surface of the Pacific plate compiled by Dr. Fuyuki Hirose at the Meteorological Research Institute. The Generic Mapping Tools (Wessel and Smith, 1995) was used to make figures. We are grateful to Dr. Naoki Uchida for his valuable comments and two anonymous reviewers for their constructive comments which were very helpful for improving the manuscript.

\section{References}

DeMets, C., R. G. Gordon, D. F. Argus, and S. Stein, Effect of recent revisions to the geomagnetic reversal time scale on estimates of current plate motions, Geophys. Res. Lett., 21, 2191-2194, 1994.
Earthquake Research Committee, Long-term evaluation of earthquakes Sanriku-oki to Boso-oki, in Publications of Earthquake Research Committee - January-December 2011-, edited by Earthquake Research Committee, The Headquarters for Earthquakes Research Promotion, 817 pp., 2012 (in Japanese).

Honda, R., Y. Yukutake, H. Ito, M. Harada, T. Aketagawa, A. Yoshida, S. Sakai, S. Nakagawa, N. Hirata, K. Obara, H. Kimura, and M. Matsubara, A broad-band rupture image of the 2011 off the Pacific coast of Tohoku Earthquake, AGU Fall Meeting, 2011.

Kanamori, H., The energy release in great earthquakes, J. Geophys. Res., 82(20), 2981-2987, 1977.

Kimura, H., K. Kasahara, T. Igarashi, and N. Hirata, Repeating earthquake activities associated with the Philippine Sea plate subduction in the Kanto district, central Japan: A new plate configuration revealed by interplate aseismic slips, Tectonophysics, 417(1), 101-118, doi:10.1016/j.tecto.2005.06.013, 2006.

Matsubara, M. and K. Obara, The 2011 off the Pacific coast of Tohoku Earthquake related to a strong velocity gradient with the Pacific plate, Earth Planets Space, 63, 663-667, 2011.

Matsumoto, S., K. Obara, K. Yoshimoto, T. Saito, A. Hasegawa, and A. Ito, Imaging of inhomogeneous structure of the crust beneath Ou backbone range, northeastern Japan, based on small aperture seismic array observations, Zisin, 52, 283-297 (in Japanese with English abstract), 1999.

Mochizuki, K., T. Yamada, M. Shinohara, Y. Yamanaka, and T. Kanazawa, Weak interplate coupling by seamounts and repeating $M \sim 7$ class earthquakes, Science, 321(5892), 2008.

Murotani, T., M. Kikuchi, and Y. Yamanaka, Source process of the 1982 Ibaraki-ken-oki earthquake inferred from JMA strong motion records, Program and abstracts the seismological society of Japan, 2003 Fall Meeting, P029, 2003.

Nagoya University, Source process of Off-Ibaraki earthquake on May 8 , 2008 (Mj 6.4, 7.0), Rep. Coord. Comm. Eathq. Predict. Jpn., 80, 108$110,2008$.

Nakajima, J. and A. Hasegawa, Cause of $M \sim 7$ intraslab earthquakes beneath the Tokyo metropolitan area, Japan: Possible evidence for a vertical tear at the easternmost portion of the Philippine Sea slab, $J$. Geophys. Res., 115, B04301, doi:10.1029/2009JB006863, 2009.

National Research Institute for Earth Science and Disaster Prevention, NIED Seismic Moment Tensor Catalogue, www.fnet.bosai.go.jp, 2012.

Nishimura, T., T. Sagiya, and R. S. Stein, Crustal block kinematics and seismic potential of the northernmost Philippine Sea plate and Izu microplate, central Japan, inferred from GPS and leveling data, J. Geophys. Res., 112, B05414, doi:10.1029/2005jB004102, 2007.

Nishimura, T., H. Munekane, and H. Yarai, The 2011 off the Pacific coast of Tohoku Earthquake and its aftershocks observed by GEONET, Earth Plantes Space, 63, 631-636, 2011.

Rost, S. and C. Thomas, Array seismology: methods and applications, Rev. Geophys., 40(3), 1008, doi:10.1029/2000RG000100, 2002.

Sella, G. F., T. H. Dixon, and A. Mao, REVEL: A model for recent plate velocities from space geodesy, J. Geophys. Res., 107(B4), 2081, doi:10.1029/2000JB000033, 2002.

Seno, T., Great earthquakes along the Nankai Trough-A new idea for their rupture mode and time series-, Zisin, 64, 97-116, 2012.

Uchida, N., J. Nakajima, A. Hasegawa, and T. Matsuzawa, What controls interplate coupling?: Evidence for abrupt change in coupling across a border between two overlying plates in the NE Japan subduction zone, Earth Planet. Sci. Lett., 283, 111-121, 2009.

Utsu, T., Seismicity Studies: A Comprehensive Review, University of Tokyo Press, 1999.

Wessel, P. and W. H. F. Smith, New version of the Generic Mapping Tools released, Eos Trans. AGU, 76, 329, 1995.

R. Honda (e-mail: ryou@onken.odawara.kanagawa.jp), Y. Yukutake, H. Ito, M. Harada, T. Aketagawa, A. Yoshida, S. Sakai, S. Nakagawa, N. Hirata, K. Obara, M. Matsubara, and H. Kimura 